\title{
Examining Individual and Ecological Predictors of the Self-Determination of Students With Disabilities
}

\author{
KARRIE A. SHOGREN \\ University of Texas at Austin \\ MICHAEL L. WEHMEYER \\ SUSAN B. PALMER \\ JANE HELEN SOUKUP \\ TODD D. LITTLE \\ NANCY GARNER \\ MARGARET LAWRENCE \\ University of Kansas
}

ABSTRACT: This article examines the impact of multiple individual and ecological factors on the self-determination of students with learning disabilities, mild and moderate mental retardation, and other health impairments. Baseline data from a multistate, longitudinal research project evaluating interventions to promote self-determination were examined using structural equation modeling. The findings suggest that teachers viewed students' capacity for self-determination differently based on level of cognitive impairment, but not students' opportunities for self-determination. Capacity, opportunity, and transition empowerment predicted students' self-reported level of self-determination, but the degree to which students were included in general education did not. Significant differences emerged in the pattern of predictive relationships, however, depending on the measure of self-determination utilized. Also discussed are implications for research and practice.

\section{SELF - DETERM INATION \\ RESEARCH}

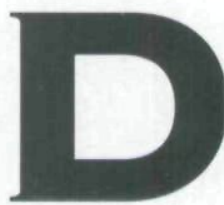

espite 15 years of attention directed toward the importance of self-determination in the education of students with disabilities, there still is a paucity of knowledge about individual and ecological factors that contribute to or predict selfdetermination. Progress has been made in developing empirically validated theoretical models of self-determination that can serve as foundations for educational practices (Wehmeyer, Abery, Mithaug, \& Stancliffe, 2003) and in synthesizing 
the existing body of research on theoretically based interventions to promote self-determination (Algozzine, Browder, Karvonen, Test, \& Wood, 2001). Additional research is needed, however, to examine the impact of personal characteristics (e.g., disability group, gender, race/ethnicity) and environmental conditions (e.g., opportunities for self-determination, inclusion) on students' relative level of self-determination. Such research has the potential to inform future efforts to design, validate, and implement interventions with students from diverse disability groups and to provide guidance in creating environmental conditions and supports that promote self-determination (Wood \& Test, 2001).

In considering individual and ecological factors that could potentially impact self-determination, the functional theory of self-determination (Wehmeyer, 1997, 1999, 2001, 2003) suggests that both environmental and personal characteristics contribute to enhanced self-determination. Specifically, the theory posits that (a) individual capacity, as influenced by learning and development; (b) opportunity, as influenced by environments and experiences; and (c) supports and accommodations all impact the emergence of selfdetermination. Further, students' perceptions and beliefs influence their capacities and opportunities for self-determination. Research on the impact of capacity and opportunity on self-determination, primarily including adults with intellectual and development disabilities, has suggested that selfdetermination tends to be significantly influenced by environmental factors. Several studies have found that adults with intellectual and developmental disabilities who live and work in more integrated settings tend to be more self-determined than are adults who live and work in segregated and congregate settings (Stancliffe, Abery, \& Smith, 2000; Wehmeyer \& Bolding, 1999, 2001). Although research findings have suggested a significant correlation between self-determination and level of intelligence-with people having more severe disabilities tending to have lower levels of self-determination (Soresi, Nota, \& Wehmeyer, in press; Wehmeyer, 1996b; Wehmeyer \& Garner, 2003)—when analyzing the predictors of high and low levels of self-determination, Wehmeyer and Garner using discriminant function analysis found that level of intelligence was not a significant contributor. Instead, having opportunities to make choices within one's environment was the only significant predictor of self-determination-confirming the importance of environmental opportunities to the development of self-determination.

Less is known about the impact of environmental factors on the self-determination of children and youth with disabilities. Zhang (2001) found that students with mild levels of intellectual disability had more opportunities to engage in self-determined behavior when they were in resource rooms than they did when in general education classrooms. This finding was contrary to expectations, given the research on the impact of integrated settings on adult's level of self-determination, but it probably speaks more to the resource room and classroom environments and the supports within them than it does to anything about the students. In fact, Zhang discussed the possibility that it might be more difficult for students with mild cognitive impairments to express self-determined behaviors in general education classrooms, particularly because general education teachers could be less knowledgeable about how to support the expression of such behaviors. Further, Zhang's research did not measure students' actual level of self-determination, but rather their expression of self-determined behaviors. Therefore, it is possible that students in more integrated settings actually could have higher levels of selfdetermination; they just might express self-determined behaviors less frequently in such settings.

\section{Zhang found that students with mild levels of intellectual disability had more} opportunities to engage in self-determined behavior when they were in resource rooms than they did when in general education classrooms.

In terms of personal characteristics, the relationship between intelligence and self-determination is significant. It is logical to assume that students' capacity for self-determination can be influenced by their level of intelligence or their disability category. As Wehmeyer and Garner 
stated, "overall self-determinations status will be impacted by limitations to the number and complexity of skills and knowledge about how to exert control in one's life that a person can acquire as a function of his or her intellectual limitations" (Wehmeyer \& Garner, 2003, p. 256). However, Wehmeyer (2006) also has suggested that the common assumption that because of his or her disability a person cannot gain the skills associated with self-determination limits the environmental opportunities and supports and accommodations provided to that person, which in turn restricts his or her ability to fully develop the capacity to act in a self-determined manner. Again, outside of intellectual disability research, there is limited information about the impact of disability category on students' level of self-determination. Aside from intellectual ability, there has been minimal research conducted regarding other personal characteristics that can impact self-determination.

\section{[T] here is limited information about the impact of disability category on students' level of self-determination.}

Soresi and colleagues (in press) examined the impact of age, gender, and social abilities on the self-determination of 141 adults with intellectual disabilities. They found no differences in self-determination across the range of ages represented in the study; however they did find differences based on gender. Women tended to be more self-determined than men-a finding that differs from prior research on gender, which found no differences in males' and females' levels of self-determination (Wehmeyer, 1996b; Wehmeyer \& Garner, 2003). Soresi and colleagues also found that social abilities were significantly correlated with self-determination, suggesting that people with higher levels of self-determination also could score higher in other domains of adaptive behavior.

Other researchers have suggested the importance of considering the impact of cultural differences on self-determination for students with disabilities who are from culturally and linguistically diverse backgrounds (Trainor, 2002, 2005). Limited research on the impact of culture on selfdetermination has been conducted, however.
Generally, self-determination theorists propose that, when considering issues related to self-determination for all students with disabilities, it is critical to consider issues related to the values, beliefs, and customs of the student and his or her family (Shogren \& Turnbull, 2006; Turnbull \& Turnbull, 1997, 2001b; Wehmeyer et al., 2003).

\section{PURPOSE OF THE STUDY}

There is limited information on the impact of individual and ecological factors on the self-determination of students with disabilities. Understanding the impact of these factors, however, is necessary to effectively design, implement, and evaluate interventions to promote the self-determination of students from diverse disability groups. The purpose of the study conducted therefore was to examine the relationship between multiple individual factors (i.e., gender, race/ethnicity, socioeconomic status, teacher ratings of students' capacity for self-determination, and student ratings of empowerment in transition services) and ecological factors (i.e., teacher ratings of students' opportunity for self-determination, students' level of inclusion, and students' attendance at their IEP meetings), and students' selfreported level of self-determination on two widely used assessments (The Arc's Self-Determination Scale and the AIR Self-Determination Scale) in students with learning disabilities, mild mental retardation, moderate mental retardation, and other health impairments.

\section{There is limited information on the impact of individual and ecological factors on the self-determination of students with disabilities. Understanding the impact of these factors, however, is necessary to effectively design, implement, and evaluate intervention. ...}

This study represented one of the first efforts to examine the relationship between multiple individual and ecological factors and students' self-reported level of self-determination. The tech- 
nique of structural equation modeling (SEM) therefore was chosen because of its flexibility in allowing examination of (a) equivalence issues related to the measurement of each construct in students with learning disabilities, mild mental retardation, moderate mental retardation, and other health impairments; and (b) potential crossgroup differences in the latent relationships among the constructs across the four groups.

The first research question focused on establishing that the six latent constructs included in the structural equation model, representing individual factors (i.e., teacher ratings of students' capacity for self-determination, student ratings of their transition empowerment), ecological factors (i.e., teacher ratings of students' opportunity for self-determination, students' level of inclusion), and self-determination (i.e., student self-report on The Arc's Self-Determination Scale and the AIR Self-Determination Scale) could be measured equivalently in each of the four disability groups. For example, differences in the characteristics or skill level of students from the diverse disability groups could influence the manner in which students and teachers responded to or interpreted questions, leading to differences in the constructs being assessed (Little, 1997). It therefore was critical to first examine whether measurement equivalence (i.e., invariance of the loadings and intercepts) could be established across the four groups. Based on previous research, primarily with assessments of self-determination in students from diverse groups (Shogren, Lopez, Wehmeyer, Little, \& Pressgrove, 2006; Shogren, Wehmeyer, et al., 2006), it was hypothesized that strong metric invariance could be established.

The second research question addressed whether there are differences across the four disability groups in the latent means of the six constructs representing individual factors, ecological factors, and self-determination. It was hypothesized that there would be significant differences in the means of several of the latent constructs in students across the four disability groups. As discussed previously, for example, research has suggested that stereotypes exist about the capacity of students for self-determination based on their level of intelligence, and that this can influence teachers' ratings of students' capacity. It also has suggested that level of intelligence is correlated to self-determination, which could lead to differences in students' ratings of their own self-determination across the four groups.

The final research question explored the degree to which the individual and ecological latent constructs, as well as categorical individual (i.e., gender, race/ethnicity, socioeconomic status) and ecological (i.e., students' attendance at their IEP meetings) variables predicted students' self-reported levels of self-determination, and whether these patterns of predictive relationships differed across the four disability groups. Based on the functional theory of self-determination, the hypothesis predicted that capacity, opportunity, and transition empowerment would predict self-determination and, based on research demonstrating the impact of the environment on self-determination, that inclusion would predict self-determination. Because of the lack of research examining the impact of categorical variables - including disability category - on self-determination, researchers did not develop a priori hypotheses and considered these aspects of the research question to be exploratory.

\section{ETHOD}

\section{PARTICIPANTS}

The study participants were 327 high school students receiving special education services in 6 states (Texas, Kansas, Missouri, Nebraska, Oklahoma, and Arkansas) in 36 school districts. The majority of students received services under the categorical label "mental retardation" $(49 \%)$ or "specific learning disability" (35\%), as shown in Table 1. Participants ranged in age from 14.3 years old to 21.8 years old $(M=17.0 ; S D=1.52)$. Females constituted $42 \%$ of the sample and males comprised $58 \%$. Female participants ranged in age from 14.8 years old to 21.8 years old $(M=$ $17.1 ; S D=1.54)$. Male participants ranged in age from 14.3 years old to 21.8 years old $(M=17.0$; $S D=1.51)$. The majority was Caucasian $(62 \%)$, although other race/ethnicities also were represented in the sample (see Table 1). Approximately $37 \%$ of students were eligible for free or reduced lunch, $40 \%$ were not eligible for free or reduced lunch, and the status of the remaining $23 \%$ of 
TABLE 1

Demographic Characteristics of the Sample

\begin{tabular}{lrr}
\hline Category & $\mathrm{n}$ & $\%$ \\
\hline Disability Category & & \\
$\quad$ Mental Retardation & & \\
$\quad$ Mild & 99 & 30.3 \\
$\quad$ Moderate & 60 & 18.3 \\
Learning Disability & 116 & 35.5 \\
Other Health Impairment & 52 & 15.9 \\
Race/Ethnicity & & \\
Caucasian & 202 & 61.8 \\
African American & 55 & 16.8 \\
Hispanic/Latino & 54 & 16.5 \\
Native American/Alaskan Native & 5 & 1.5 \\
Asian/Pacific Islander & 1 & 0.3 \\
Other & 10 & 3.1 \\
\hline
\end{tabular}

students was reported by the teachers as being unknown. Approximately $91 \%$ of students had attended their last IEP meeting.

\section{PROCEDURE}

Participants were recruited to participate in a 5 year longitudinal study examining the impact of interventions to promote self-determination on student self-determination and postschool outcomes. Project personnel contacted school districts, and districts that agreed to participate ( $n=$ 36) identified students who met the project criteria, which included high school students receiving special education services who also were expected to be receiving services for an additional 2 years after project implementation. The requirement that students be expected to receive services for an additional 2 years after project implementation was to ensure that there was sufficient time for students to benefit from self-determination interventions in educational settings. Informed consent was obtained for each participant from his or her parent or guardian, as well as assent from the student.

After consent and assent to participate were obtained, baseline data were collected prior to intervention implementation. Baseline data consisted of demographic information about the student and his or her educational experiences, and multiple measures of self-determination and student empowerment completed by students and teachers (described subsequently). Students' baseline data were used for the analyses reported here. After being trained in the appropriate administration protocol, teachers and project personnel administered the measures to participating students in individual or group sessions, depending upon the needs of the students and the school district.

\section{DEMOGRAPHIC INFORMATION}

Teachers completed a demographic form that included basic information about each student, such as date of birth, gender, race/ethnicity, free/reduced lunch status, and the disability category under which the student received special education services. The form also included questions related to the type of special education services students received. For example, teachers were asked to provide information about the setting in which the student typically received services (e.g., general education classroom, resource room, segregated classroom, segregated school, home/hospital) and the number of hours each day the student typically spent with his or her nondisabled peers. Teachers also were asked to provide information about each student's previous involvement in the transition planning process, such as whether the student had attended his or her last IEP meeting.

\section{MEASURES OF SELF-DETERMINATION}

The Arc's Self-Determination Scale. The Arc's Self-Determination Scale (SDS; Wehmeyer \& Kelchner, 1995) is a 72 -item self-report measure that provides data on self-determination through the measurement of the four essential characteristics of self-determined behavior: autonomy, selfregulation, psychological empowerment, and self-realization (Wehmeyer, 1996a). Subscale scores can be calculated for the autonomy, selfregulation, psychological empowerment, and selfrealization domains, along with a total self-determination score. The scale consists of a total of 148 points, with higher scores indicating higher levels of self-determination. The SDS was developed and normed with 500 adolescents with cognitive disabilities (Wehmeyer, 1996c). It was demonstrated to have adequate reliability and validity in the measurement of self-determination for adolescents with cognitive disabilities. Subse- 
quent research (Shogren, Lopez, et al., 2006; Shogren, Wehmeyer, et al., 2006) has verified the proposed theoretical structure of The Arc's SelfDetermination Scale (i.e., four related, but distinct subscales-autonomy, self-regulation, psychological empowerment, and self-realization-that contribute to a higher-order self-determination construct), using structural equation modeling. In this study, Cronbach's alpha for the SDS was 0.89 .

The AIR Self-Determination Scale. The AIR Self-Determination Scale (AIR; Wolman, Campeau, Dubois, Mithaug, \& Stolarski, 1994) is available in a Student, Educator, and Parent version. For the purposes of these analyses, the Educator (AIR-E) and Student (AIR-S) versions of the scale were utilized. The AIR-E has 30 questions from which capacity and opportunity subscale scores can be calculated. The capacity subscale asks teachers to report on a given student's (a) ability to perform self-determination behaviors, (b) knowledge of self-determination behaviors, and (c) perception of knowledge and ability to perform self-determination behaviors. The opportunity subscale consists of information on students' opportunity to perform self-determination behaviors at school and at home; however, because a substantial number of teachers $(21 \%$ of the sample) reported an inability to report on students' self-determination behaviors at home, the six questions on this domain were dropped from the analyses. Thus, the opportunity domain consisted only of teacher ratings of students' opportunity to perform self-determined behaviors at school, and the version of the AIR-E utilized in this study consisted of 24 questions rated on a scale from 1 (Never) to 5 (Always).

The AIR-S has 24 questions and also yields capacity and opportunity subscale scores. The capacity subscale consists of questions related to things students do related to self-determination ("Things I Do" subscale) and how students feel about performing these self-determined behaviors ("How I Feel" subscale). The opportunity subscale consists of questions regarding students' perceptions of their opportunities to perform self-determined behaviors at home and at school; however, as mentioned previously, the information on the home subscale was dropped to keep the two versions of the AIR parallel in these anal- yses. As such, the AIR-S consisted of 18 questions rated on a scale of 1 (Never) to 5 (Always).

The AIR was developed and normed with 450 students (with and without disabilities) and their teachers in California and New York (Wolman et al., 1994). The AIR was demonstrated to have adequate reliability and validity in the measurement of students' capacity and opportunity for self-determination (Mithaug, Campeau, \& Wolman, 2003). In this study Cronbach's alpha for the AIR-E capacity subscale was 0.93 , for the opportunity subscale it was 0.92 , and for the AIR-S it was 0.92 . The authors of the AIR suggested that a total self-determination score also can be calculated by combining the capacity and opportunity subscales on both the AIR-E and AIR-S. More recent research (Shogren, Wehmeyer, et al., 2006), however, has suggested that combining the capacity and opportunity subscales into a higher-order self-determination construct on the AIR-E is not justified. Specifically, using structural equation modeling, Shogren, Wehmeyer, and colleagues (2006) explored the theoretical structure of and the relationship between the AIR-E, the AIR-S, and the SDS. The proposed theoretical structure of both the SDS and the AIR-S was supported by these analyses. Additionally, the analyses suggested that although the SDS and the AIR-S were related $(r=0.50)$, they were measuring distinct aspects of the selfdetermination construct. Combining these two measures into one global, higher-order self-determination construct was not supported by the data.

Unlike for the AIR-S, Shogren, Wehmeyer, and colleagues (2006) found that the proposed theoretical structure of the AIR-E was not supported by the data. Instead, the analyses suggested that the AIR-E is assessing two distinct constructs - capacity and opportunity - that could not be combined to create a higher-order self-determination construct. The correlation between the two constructs was only 0.34 , and efforts to fit a model specifying the proposed theoretical structure of the AIR-E (capacity and opportunity constructs loading on a higher-order self-determination construct) resulted in extreme difficulties with model convergence (Shogren, Wehmeyer, et al., 2006). Educators therefore appear to be providing objective ratings of their independent 
perceptions of students' capacity and opportunity for self-determination, unlike students, who-on the AIR-S - appear to provide ratings of their overall self-determination based on the strong relationship they perceive between their capacity and opportunity for self-determination. Given the findings of Shogren, Wehmeyer, et al. (2006), in these analyses the researchers chose to create two distinct latent constructs for the AIR-E, representing capacity and opportunity, and to create one latent construct for the AIR-S, representing self-determination. The latent constructs of capacity and opportunity were used as objective indicators of students' capacity and opportunity for self-determination, and the degree to which these constructs predicted self-determination (as proposed by the functional theory of self-determination) as measured by both the SDS and the AIR-S was examined.

The Transition Empowerment Scale. The Transition Empowerment Scale (TES; Powers, Turner, et al., 2001) is a measure of youth empowerment within the context of the transition planning process. The measure is an adaptation of the Family Empowerment Scale (Koren, DeChillo, \& Friesen, 1992), which was originally developed to enable parents of children with emotional and behavioral disorders to report on their family empowerment. In adapting the Family Empowerment Scale, the questions were modified to enable adolescents with disabilities to self-report on the extent to which they could "manage their own day-to-day circumstances, services, and advocate for other youth" (Powers, Turner, et al., 2001, p. 94). The TES consists of 31 questions rated on a scale of 0 (Not True at All) to 4 (Very True). Research on the TES has suggested adequate reliability and validity in the measurement of adolescent empowerment (Powers, Ellison, et al., 2001; Powers, Turner, et al., 2001). In this study, the Cronbach's alpha value for this measure was 0.94 .

\section{MISSING DATA}

A small amount of data was missing for several variables. The mean percentage of missing data across all of the variables in the data set was 1.5\% (range 0 to $4.1 \%$ ). The EM imputation algorithm using the PROC MI procedure within the SAS program was used to impute the missing data
(Graham, Cumsille, \& Elek-Fisk, 2003) using the totality of information within the data set to impute the missing data to preserve important characteristics of the data set and avoid the potential deleterious effects of not including all available data in the data-analysis process. Doing so improved the ability to calculate unbiased and efficient parameter estimates (Graham et al.).

\section{ANALYTIC PROCEDURES}

Structural equation modeling was used to examine the research questions. Structural equation modeling allows researchers to flexibly and powerfully examine the relationships between observed and latent variables, as well as to test cross-group similarities and differences among multiple latent variables (Kline, 1998). The procedures involve integration of measurement models (which specify the relationships among latent and observed variables) with structural models (which specify the relationship between latent factors). Specifically, this enables the measurement equivalence of the constructs across groups to be assessed, and direct statistical comparisons of the similarities and differences in the means, variances, correlations, and regression relationships among the constructs to be made (Little, 1997). This study focused on examining measurement equivalence and possible latent differences among the different disability groups represented in the sample.

Four groups were created (learning disability, mild mental retardation, moderate mental retardation, and other health impairment). Prior to evaluating the measurement model across the disability groups, researchers conducted preliminary regression analyses to evaluate the potential impact of several of the categorical personal and environmental characteristics (i.e., gender, race/ethnicity, free/reduced lunch status, attendance at last IEP meeting) to determine if, and how, they should be included in the model. Each of these characteristics was regressed as well as, for each variable, a characteristic $\times$ disability group interaction variable, on students' total scores on The Arc's Self-Determination Scale and the AIR Self-Determination Scale, Student version. The only significant relationship in the preliminary regression analyses was the relationship between 
gender and self-determination as measured by The Arc's Self-Determination Scale $(\beta=0.27, t=$ $2.86, p=0.005)$. Thus, gender was included as a covariate (female $=0$; male $=1$ ) in the structural model to examine and control for potential differences across male and female students. (For additional information on the preliminary regression analyses please contact the authors.)

To evaluate the hypothesized measurement and structural models, researchers sequentially tested the following models: (a) a test of the measurement model that specified the relationship between manifest indicators (e.g., observed variables) and latent constructs (e.g., unobserved variables); (b) a test of the measurement equivalence in the measurement of these indicators across students with learning disabilities, mild mental retardation, moderate mental retardation, and other health impairments (e.g., the equating of the loadings and intercepts of the observed variables across groups); (c) a test of the homogeneity of the variances and covariances of the latent constructs in students with learning disabilities, mild mental retardation, moderate mental retardation, and other health impairments; (d) a test of the equivalence of the means of the latent constructs in students with learning disabilities, mild mental retardation, moderate mental retardation, and other health impairments; and (e) tests of the structural models that specify the causal relationship between the latent constructs in students with learning disabilities, mild mental retardation, moderate mental retardation, and other health impairments (Kline, 1998; Little, 1997).

The measurement model contained six latent constructs: capacity (AIREC), opportunity (AIREO), transition empowerment (TES), inclusion (INC), self-determination as measured by The Arc's Self-Determination Scale (SDS), and self-determination as measured by the AIR SelfDetermination Scale, Student version (AIR-S). For the latent constructs of opportunity and transition empowerment, domain-representative parcels were created to form three manifest indicators for each latent construct. Parceling is a commonly used technique for measures such as these; a parcel can be defined as "an aggregatelevel indicator comprised of the sum (or average) of two or more items, responses, or behaviors"
(Little, Cunningham, Shahar, \& Widaman, 2002, p. 152). Parceling introduces advances over itemlevel modeling, including greater parsimony, fewer chances for correlated residuals or dual loadings of indicators, and reductions in sampling error (Little et al., 2002). To create parcels for the opportunity and transition empowerment constructs, the item-to-construct balancing technique was utilized (see Little et al., 2002, for details).

For the capacity, self-determination (SDS), and self-determination (AIR-S) constructs, facetrepresentative parcels were created based on the subdomains within the subscales. Three facet-representative parcels were used as indicators for the capacity construct, representing the three subdomains of ability, knowledge, and perceptions on the AIR-E capacity subscale. Four facet-representative parcels were used as indicators for SDS, representing the four subscales (essential characteristics) of self-determined behavior measured by the SDS: autonomy, self-regulation, psychological empowerment, and self-realization. Two facet-representative parcels were used an indicators for the AIR-S, representing the two subscales of capacity and opportunity. For the inclusion construct, two indicators of inclusion were utilized. Based on teachers' responses on the demographic form to the typical education setting students were educated in and the number of $\mathrm{hr}$ the student spent under special education supervision, a new variable was created, called IDEA Setting, that specified the percentage of time that the student spent outside of the general education classroom. The categories were created based on those specified within the U.S. Department of Education's 24th Annual Report to Congress on the Implementation of the Individuals with Disabilities Education Act (2002) $(1=$ home/hospital; 2 = separate day school; $3=$ more than $60 \%$ of time outside of general education; $4=21 \%-60 \%$ of time outside of general education; and $5=$ less than $20 \%$ of time outside of general education). The second indicator of the latent construct of inclusion was the teachers' ratings of the average number of hours students spent with their nondisabled peers each day $(1=0 \mathrm{hr} ; 2=$ less than $1 \mathrm{hr} ; 3=$ between 1 and $3 \mathrm{hr} ; 4=$ between 3 and $5 \mathrm{hr} ; 5=$ full day). Table 2 provides the number and percentage of students by disability category across each of these variables. 


\begin{tabular}{|c|c|c|c|c|}
\hline Variables & $\begin{array}{c}L D \\
\mathrm{n}(\%)\end{array}$ & $\begin{array}{c}M L M R \\
\mathrm{n}(\%)\end{array}$ & $\begin{array}{c}M D M R \\
\mathrm{n}(\%)\end{array}$ & $\begin{array}{c}\mathrm{OHI} \\
\mathrm{n}(\%)\end{array}$ \\
\hline \multicolumn{5}{|l|}{ IDEA Setting } \\
\hline Home/hospital & $3(2.6)$ & $4(4.0)$ & $2(3.3)$ & $1(1.9)$ \\
\hline Separate day school & $1(0.9)$ & $6(6.1)$ & $6(10.0)$ & $2(3.8)$ \\
\hline $60 \%$ of time outside general education & $10(8.6)$ & $37(37.4)$ & $37(61.7)$ & $12(23.1)$ \\
\hline $21 \%-60 \%$ of time outside general education & $41(35.3)$ & $33(33.3)$ & $11(18.3)$ & $16(30.8)$ \\
\hline$<20 \%$ of time outside general education & $61(52.6)$ & $19(19.2)$ & $4(6.7)$ & $21(40.4)$ \\
\hline \multicolumn{5}{|l|}{ Hours per Day With Nondisabled Peers } \\
\hline $0 \mathrm{hr}$ & $1(0.9)$ & $8(8.1)$ & $10(16.7)$ & $0 \quad(0.0)$ \\
\hline Less than $1 \mathrm{hr}$ & $1(0.9)$ & $7(7.1)$ & $11(18.3)$ & $3(5.8)$ \\
\hline Between 1 and $3 \mathrm{hr}$ & $29(25.0)$ & $38(38.4)$ & $28(46.7)$ & $16(36.5)$ \\
\hline Between 3 and $5 \mathrm{hr}$ & $61(52.6)$ & $39(37.4)$ & $11(18.3)$ & $21(40.4)$ \\
\hline Full day & $24(20.7)$ & $7(7.1)$ & $0 \quad(0.0)$ & $9(17.3)$ \\
\hline
\end{tabular}

Note. $\mathrm{LD}=$ Learning disability; $\mathrm{MLMR}=$ Mild mental retardation; $\mathrm{MDMR}=$ Moderate mental retardation; $\mathrm{OHI}=$ Other health impairment.

Instead of using traditional methods such as setting the latent variance to equal 1.0 , or setting one indicator to equal 1.0 to set the scale, this study used a balancing technique which allowed the scale to be set by constraining the sum of the indicator's loadings to be equal to the number of indicators (e.g., sample LISREL syntax: CO $\mathrm{LY}(1,1)=3-\mathrm{LY}(2,1)-\mathrm{LY}(3,1))$. Using this technique, researchers could estimate each construct's latent variance in a non-arbitrary metric (the effects coding method, see Little, Slegers, \& Card, 2006, for more information), a procedure that cannot be performed with the traditional methods mentioned previously. A similar procedure was used to define and set the scale of the intercepts such that the latent means could be estimated in a non-arbitrary metric (e.g., sample LISREL syntax: CO TY(1) $=0-\mathrm{TY}(2)-\mathrm{TY}(3))$.

To test the hypothesized structural models, the correlational relationships specified in the measurement model between capacity, opportunity, transition empowerment, and inclusion and self-determination as measured by both the SDS and the AIRS were converted into regression paths to analyze the degree to which each of these latent constructs predicted self-determination. Gender also was added as an exogenous variable to evaluate and control for its impact on each of the latent constructs in the structural model.

\section{RESULTS}

\section{MEASUREMENT MODELS}

The initial, freely estimated, measurement model demonstrated acceptable model fit $\left(\chi^{2}\right.$ (416, $n=$ $327)=570.02, p=<0.001$, RMSEA $=0.057$, NNFI $=0.95$, CFI $=0.96$ ). Next, following standard procedures to evaluate measurement invariance, the loadings and the intercepts were equated (in sequential steps) and, as shown in Table 3, no significant changes in fit were found based on the RMSEA Model Test (i.e., does the RMSEA value of the nested model fall within the 90\% RMSEA confidence interval of the comparison model; Little, 1997; also note that changes in the CFI were less than 0.01 , see Cheung \& Rensvold, 2002). These tests indicated that the constructs included in the model (capacity, opportunity, transition empowerment, inclusion, self-determination [SDS], and self-determination [AIR-S]) were invariant when measured across the four disability groups. Essentially the same constructs were being assessed in students across the diverse disability categories.

The loading and intercept values for each indicator, along with the variance for each latent construct in the strong metric invariant model, are presented in Table 4 . The unique residual and 


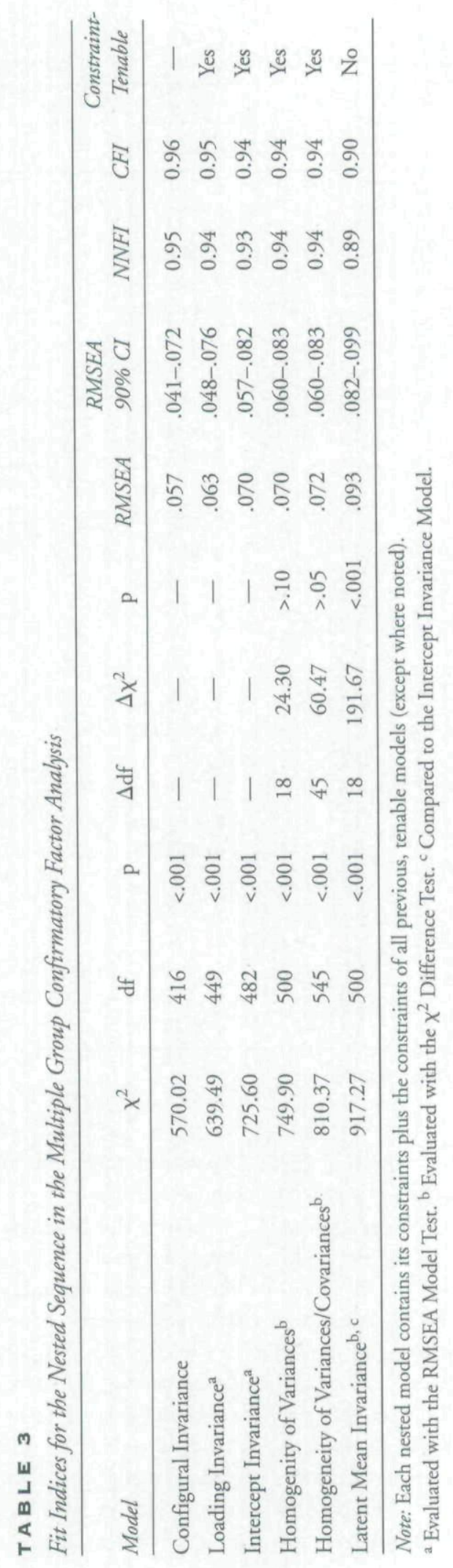


Loading and Intercept Values and the Estimated Latent Variance From the Strong Metric Invariance Model

\begin{tabular}{|c|c|c|c|}
\hline \multirow[b]{2}{*}{ Indicator } & \multicolumn{2}{|c|}{ Estimates } & \multirow{2}{*}{$\frac{\text { Standardized }}{\text { Loading }^{a}}$} \\
\hline & Loading (SE) & Intercept (SE) & \\
\hline \multicolumn{4}{|l|}{$\begin{array}{l}\text { AIR-E Capacity Subscale (AIREC): } \\
\text { Estimated Latent Variance }=0.63\end{array}$} \\
\hline Parcel 1 & $1.09(0.03)$ & $0.01(0.02)$ & 0.91 \\
\hline Parcel 2 & $1.03(0.03)$ & $-0.03(0.02)$ & 0.84 \\
\hline Parcel 3 & $0.88(0.03)$ & $0.02(0.03)$ & 0.72 \\
\hline \multicolumn{4}{|l|}{$\begin{array}{l}\text { AIR-E Opportunity Subscale (AIREO): } \\
\text { Estimated Latent Variance }=0.85\end{array}$} \\
\hline Parcel 1 & $0.99(0.02)$ & $0.02(0.02)$ & 0.92 \\
\hline Parcel 2 & $1.02(0.02)$ & $-0.01(0.02)$ & 0.94 \\
\hline Parcel 3 & $0.99(0.02)$ & $-0.01(0.02)$ & 0.91 \\
\hline \multirow{2}{*}{\multicolumn{4}{|c|}{$\begin{array}{l}\text { Transition Empowerment Scale (TE): } \\
\text { Estimated Latent Variance }=0.85\end{array}$}} \\
\hline & & & \\
\hline Parcel 1 & $1.00(0.02)$ & $0.00(0.02)$ & 0.92 \\
\hline Parcel 2 & $1.00(0.02)$ & $0.00(0.02)$ & 0.91 \\
\hline Parcel 3 & $1.00(0.02)$ & $-0.01(0.02)$ & 0.92 \\
\hline \multirow{2}{*}{\multicolumn{4}{|c|}{$\begin{array}{l}\text { Inclusion (INC): } \\
\text { Estimated Latent Variance }=0.31\end{array}$}} \\
\hline & & & \\
\hline IDEA Setting & $1.02(0.06)$ & $0.00(0.03)$ & 0.64 \\
\hline Hours Per Day with Nondisabled Peers & $0.98(0.06)$ & $0.00(0.03)$ & 0.60 \\
\hline \multirow{2}{*}{\multicolumn{4}{|c|}{$\begin{array}{l}\text { Self-Determination }(\mathrm{SDS}): \\
\text { Estimated Latent Variance }=0.27\end{array}$}} \\
\hline & & & \\
\hline Autonomy & $0.99(0.08)$ & $-0.03(0.04)$ & 0.53 \\
\hline Self-Regulation & $0.98(0.08)$ & $0.00(0.04)$ & 0.51 \\
\hline Psychological Empowerment & $1.12(0.08)$ & $0.02(0.04)$ & 0.60 \\
\hline Self-Realization & $0.91(0.08)$ & $0.01(0.04)$ & 0.48 \\
\hline \multicolumn{4}{|l|}{$\begin{array}{l}\text { Self-Determination (AIRS): } \\
\text { Estimated Latent Variance }=0.69\end{array}$} \\
\hline Capacity & $1.14(0.04)$ & $0.00(0.02)$ & 0.93 \\
\hline Opportunity & $0.86(0.04)$ & $0.00(0.02)$ & 0.71 \\
\hline
\end{tabular}

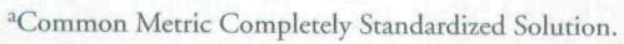

$R^{2}$ values for each indicator across the four disability groups are presented in Table 5 .

The homogeneity of the variances and covariances of the latent constructs also were evaluated using the $\chi^{2}$ Difference Test (i.e., is there a nonsignificant change in $\chi^{2}$ when the constraint is added to the model). The test revealed no significant differences in the variances and covariances of the latent constructs across the four disability groups (as shown in Table 3), indicating equivalent variances and patterns of covariances/correlations across the four disability groups. The common correlations between the constructs across the disability groups are presented in Table 6.

Then the relationships between the latent means across the four groups were evaluated. Unlike the latent variances and covariances, the latent means were not invariant across the groups $\left(\Delta \chi^{2}(18, n=327)=191.67, p<0.001\right)$. In visually inspecting the pattern of latent means, which were standardized to have a mean of zero and a standard deviation of 1.0 across the disability groups, it appeared that several of the latent constructs had greater variability across the four groups. Thus, nested $\chi^{2}$ difference tests were per- 


\begin{tabular}{|c|c|c|c|c|c|c|c|c|}
\hline \multirow[b]{2}{*}{ Indicator } & \multicolumn{2}{|c|}{$L D$} & \multicolumn{2}{|c|}{$M L M R$} & \multicolumn{2}{|c|}{$M D M R$} & \multicolumn{2}{|c|}{$\mathrm{OHI}$} \\
\hline & Theta & $\mathrm{R}^{2}$ & Theta & $\mathrm{R}^{2}$ & Theta & $\mathrm{R}^{2}$ & Theta & $\mathrm{R}^{2}$ \\
\hline
\end{tabular}

AIR-E Capacity Subscale (AIREC)

$\begin{array}{lllllllll}\text { Parcel 1 } & 0.18(0.04) & 0.81 & 0.07(0.03) & 0.91 & 0.12(0.07) & 0.87 & 0.27(0.07) & 0.74 \\ \text { Parcel 2 } & 0.04(0.02) & 0.95 & 0.13(0.03) & 0.84 & 0.96(0.24) & 0.36 & 0.02(0.04) & 0.98 \\ \text { Parcel 3 } & 0.37(0.05) & 0.57 & 0.45(0.07) & 0.52 & 0.56(0.12) & 0.47 & 0.51(0.10) & 0.49\end{array}$

AIR-E Opportunity Subscale (AIREO)

$\begin{array}{lllllllll}\text { Parcel 1 } & 0.09(0.02) & 0.90 & 0.15(0.03) & 0.84 & 0.34(0.08) & 0.71 & 0.12(0.04) & 0.87 \\ \text { Parcel 2 } & 0.09(0.02) & 0.91 & 0.10(0.03) & 0.90 & 0.16(0.05) & 0.85 & 0.14(0.04) & 0.86 \\ \text { Parcel 3 } & 0.19(0.03) & 0.82 & 0.18(0.03) & 0.83 & 0.16(0.05) & 0.84 & 0.13(0.04) & 0.87\end{array}$

Transition Empowerment Scale (TE)

$\begin{array}{lllllllll}\text { Parcel 1 } & 0.16(0.03) & 0.84 & 0.09(0.03) & 0.91 & 0.20(0.05) & 0.81 & 0.18(0.05) & 0.83 \\ \text { Parcel 2 } & 0.12(0.02) & 0.88 & 0.21(0.04) & 0.80 & 0.24(0.06) & 0.78 & 0.14(0.04) & 0.86 \\ \text { Parcel 3 } & 0.13(0.03) & 0.87 & 0.18(0.04) & 0.83 & 0.11(0.04) & 0.88 & 0.15(0.04) & 0.85\end{array}$

Inclusion (INC)

IDEA Setting

$0.45(0.09) \quad 0.42$

$0.53(0.11) \quad 0.38$

$0.33(0.11) \quad 0.50$

$0.55(0.15) \quad 0.37$

Hours per Day with

Nondisabled Peers

$$
0.35(0.09) \quad 0.46
$$

$0.67(0.13) \quad 0.31$

$0.75(0.17) \quad 0.28$

$0.33(0.11) \quad 0.47$

Self-Determination (SDS)

Autonomy
Self-Regulation
Psychological
$\quad$ Empowerment
Self-Realization

$\begin{array}{llll}0.47(0.07) & 0.36 & 0.93(0.15) & 0.22 \\ 0.69(0.10) & 0.2 & 0.75(0.12) & 0.26 \\ & & & \\ 0.32(0.06) & 0.51 & 0.73(0.12) & 0.32 \\ 0.60(0.09) & 0.25 & 0.90(0.14) & 0.19\end{array}$

$0.90(0.18) \quad 0.23$

$0.49(0.12) \quad 0.35$

$0.71(0.15) \quad 0.26$

$0.70(0.15) \quad 0.27$

Self-Determination (AIRS)

\begin{tabular}{lllllllll} 
Capacity & $0.19(0.08)$ & 0.82 & $0.11(0.07)$ & 0.89 & $0.03(0.07)$ & 0.98 & $0.18(0.10)$ & 0.83 \\
Opportunity & $0.54(0.09)$ & 0.49 & $0.40(0.07)$ & 0.56 & $0.68(0.13)$ & 0.43 & $0.42(0.10)$ & 0.55 \\
\hline
\end{tabular}

Note. $\mathrm{LD}=$ Learning disability group; $\mathrm{MLMR}=$ Mild mental retardation group; $\mathrm{MDMR}=$ Moderate mental retardation group; $\mathrm{OHI}=$ Other health impairment group.

TABLE 6

Correlations Between Latent Constructs

\begin{tabular}{lcccccc}
\hline & AIREC & AIREO & TE & INC & SDS & AIRS \\
\hline AIREC & 1.00 & & & & & \\
AIREO & 0.32 & 1.00 & & & & \\
TE & 0.20 & 0.12 & 1.00 & & & \\
INC & 0.21 & -0.15 & -0.07 & 1.00 & 1.00 & \\
SDS & 0.50 & 0.14 & 0.57 & 0.08 & 0.58 & 1.00 \\
AIRS & 0.20 & 0.11 & 0.71 & -0.05 & \\
\hline
\end{tabular}

Note. AIREC $=$ AIR Educator Capacity Subscale; AIREO = AIR Educator Opportunity Subscale; TE = Transition Empowerment Scale; INC = Inclusion; SDS = Self-Determination as measured by The Arc's Self-Determination Scale; AIRS $=$ Self-Determination as measured by the AIR Self-Determination Scale-Student. 


\begin{tabular}{|c|c|c|c|c|c|c|c|c|}
\hline Constructs & $x^{2}$ & $d f$ & $\mathrm{P}$ & $\Delta \chi^{2}$ & $\Delta d f$ & $\mathrm{p}$ & $\begin{array}{c}\text { Equivalent } \\
\text { Across } \\
\text { Groups }\end{array}$ & $\begin{array}{c}\text { Equivalent } \\
\text { Latent } \\
\text { Mean }(\mathrm{SE})\end{array}$ \\
\hline $\begin{array}{l}\text { Intercept Invariance } \\
\text { (Baseline Model) }\end{array}$ & 725.60 & 482 & $<.001$ & - & - & - & - & - \\
\hline AIRE Capacity & 760.83 & 485 & $<.001$ & 35.23 & 3 & $<.001$ & No & - \\
\hline AIRE Opportunity & 729.77 & 485 & $<.001$ & 4.17 & 3 & $>.05$ & Yes & $0.04(0.05)$ \\
\hline Transition & & & & & & & & \\
\hline Empowerment & 729.17 & 485 & $<.001$ & 3.57 & 3 & $>.05$ & Yes & $0.00(0.05)$ \\
\hline Inclusion & 810.31 & 485 & $<.001$ & 84.71 & 3 & $<.001$ & No & - \\
\hline Self-Determination (SDS) & 758.90 & 485 & $<.001$ & 33.30 & 3 & $<.001$ & No & - \\
\hline Self-Determination (AIRS) & 725.95 & 485 & $<.001$ & 0.35 & 3 & $>.05$ & Yes & $0.01(0.05)$ \\
\hline
\end{tabular}

Note. Indicators are standardized to have a mean of 0 and standard deviation of 1.0 across the groups.

formed for each of the individual latent means across the disability groups to determine what latent means were driving the differences. As shown in Table 7, it was differences in the capacity, inclusion, and self-determination (SDS) constructs that were driving the differences. Thus, the opportunity, transition empowerment, and self-determination (AIR-S) constructs were equated across each of the disability groups. The equated values are presented in Table 7.

Next, researchers evaluated whether, for the capacity, inclusion, and self-determination (SDS) constructs, it could be possible to equate the latent means across two or more of the disability groups. Using background knowledge of the characteristics of students from the disability groups, first the possibility of equating capacity, inclusion, and self-determination (SDS) across the learning disability (LD) and other health impairment $(\mathrm{OHI})$ group was evaluated. The non-significant change in model fit $\left(\Delta \chi^{2}(3, n=327)=6.83, p>\right.$ 0.05 ) indicated this constraint was justified. Whether the mild mental retardation (MLMR) group's latent mean values could be equated to the $\mathrm{LD}$ and $\mathrm{OHI}$ groups was assessed next and it was found that they could not $\left(\Delta \chi^{2}(3, n=327)\right.$ $=52.76, p<0.001)$. Last, it was determined whether the values for the moderate mental retardation group (MDMR) could be equated to the MLMR group; they could not $\left(\Delta \chi^{2}(3, n=327)\right.$
$=26.41, p<0.001)$. The final values for latent means of capacity, inclusion, and self-determination (SDS) are presented in Table 8. As shown in Table 8, the LD/OHI group tended to have the highest means across all three constructs, followed by the MLMR group, and the MDMR group.

\section{STRUCTURAL MODELS}

Given that, in evaluating the measurement model, the homogeneity of the variances and covariances across the four disability groups was established, in evaluating the structural models, the data was able to be collapsed across the four groups after controlling for the mean-level differences by mean standardizing the indicators within each of the four groups. The initial structural model for the full data set, which included gender as a covariate, demonstrated acceptable model fit $\left(\chi^{2}(115, n=327)=270.30, p=<0.001\right.$, RMSEA $=0.065, \mathrm{NNFI}=0.95, \mathrm{CFI}=0.96$ ). The only variable that gender exerted a significant influence upon was self-determination (SDS) $(\gamma=$ $-0.19, z=-2.64, p<0.05)$, with females tending to have higher levels of self-determination as measured by the SDS.

This research focused on the degree to which the various constructs (capacity, opportunity, transition empowerment, and inclusion) predicted self-determination as measured by the SDS and AIR-S; therefore, we next examined the re- 

Groups

\begin{tabular}{lccc}
\hline Constructs & $\begin{array}{c}\text { LD/OHI } \\
\text { Latent Mean }(\mathrm{SE})\end{array}$ & $\begin{array}{c}\text { MLMR } \\
\text { Latent Mean }(\mathrm{SE})\end{array}$ & $\begin{array}{c}\text { MDMR } \\
\text { Latent Mean }(\mathrm{SE})\end{array}$ \\
\hline Capacity & $0.21(0.06)$ & $-0.05(0.08)$ & $-0.54(0.08)$ \\
Inclusion & $0.44(0.05)$ & $-0.22(0.08)$ & $-0.74(0.09)$ \\
Self-Determination & $0.23(0.04)$ & $-0.20(0.07)$ & $-0.24(0.08)$ \\
\hline
\end{tabular}

Note. Indicators are standardized to have a mean of zero and standard deviation of 1.0 across the groups. LD = Learning disability group; $M L M R=$ Mild mental retardation group; $M D M R=$ Moderate mental retardation group; $\mathrm{OHI}=\mathrm{Other}$ health impairment group.

gression weights for each of these relationships. First, nonsignificant regression paths were sequentially removed from the model. In the initial structural model, opportunity did not predict self-determination as measured by the AIR-S ( $\beta=$ $0.01, z=0.14, p>0.05)$, and so this path was dropped from further analysis. After removing the path between opportunity and the AIR-S, the next lowest nonsignificant path was between inclusion and the SDS $(\beta=0.12, z=0.83 ; p>$ $0.05)$, and this path was dropped from further analysis. After removing the path between opportunity and the AIR-S, the last nonsignificant path was between inclusion and the AIR-S $(\beta=-0.03$, $z=-0.67 p>0.05$ ), and therefore this path was dropped from further analyses. All remaining paths were significant. Then the equivalence of the common paths between capacity and transition empowerment and self-determination as measured by the SDS and AIR-S was sequentially tested. It was found that equating the common paths between capacity and transition empowerment and the SDS and AIR-S was not justified, $\Delta \chi^{2}(2, n=327)=30.92, p<0.0001$. Next the shared paths for each individual construct and its relationship with the SDS and AIR-S were sequentially tested. It was differences in the paths between capacity and the SDS and AIR-S that were driving the differences, capacity, $\Delta \chi^{2}(1, n=$ $327)=30.90, p<0.0001$. The paths between transition empowerment and the SDS and AIR-S could be equated, $\Delta \chi^{2}(1, n=407)=0.02, p>$ 0.005 . The beta values from the final structural model are presented in Table 9.

\section{DISCUSSION}

The purpose of this research was to examine the impact of multiple individual and ecological factors on students' self-reported levels of self-determination on two widely used measures of self-determination, The Arc's Self-Determination Scale and the AIR Self-Determination Scale. Using the flexible SEM framework, researchers were able to explore the pattern of relationships among these factors in students with learning disabilities, mild mental retardation, moderate mental retardation, and other health impairments. In exploring the implications of the findings, the discussion section is divided into three sections: summary of the findings, limitations of the study, and implications for research and practice.

\section{SUMMARY OF FINDINGS}

Measurement Equivalence. With regard to the first research question, an important first step in research examining multiple latent constructs across diverse groups is to ensure that the same constructs are being measured in each of the groups (Little, 1997). Finding that measurement invariance could be established for each of the latent constructs across the four groups (see Table 3) provided a basis to assume that, because the constructs were defined in the same operational manner in each group, the construct's variance, correlation, and mean-level differences could be compared meaningfully and with quantitative precision (Little). This enabled examination of the research questions related to cross-group differences, and it suggests that, in future research, these assessments can be utilized effectively with 


\begin{tabular}{lcccc}
\hline Construct & Beta $(\mathrm{SE})$ & $\mathrm{z}$-score & p-value & Standardized Beta ${ }^{2}$ \\
\hline Path to Self-Determination-The Arc's Self-Determination Scale & & & \\
Capacity & $0.89(0.16)$ & 5.62 & $<.05$ & 0.66 \\
Opportunity & $0.28(0.09)$ & 3.03 & $<.05$ & 0.19 \\
Transition Empowerment & $0.49(0.03)$ & 14.95 & $<.05$ & 0.33 \\
Inclusion & - & - & - & - \\
Path to Self-Determination-The AIR Self-Determination & Assessment-Student & Version & \\
Capacity & $-0.18(0.08)$ & -2.25 & $<.05$ & -0.20 \\
Opportunity & - & - & - & - \\
Transition Empowerment & $0.49(0.03)$ & 14.94 & $<.05$ & 0.50 \\
Inclusion & - & - & - & - \\
\hline
\end{tabular}

${ }^{2}$ Completely Standardized Solution

students having diverse levels of cognitive impairment.

Mean-Level Differences. With regard to the second research question, findings showed that there are distinct patterns of similarities and differences in the latent means across the four disability groups, thus confirming the general research hypothesis that there would be differences across the groups on several of the latent constructs. Specifically, it was found that the opportunity, transition empowerment, and self-determination (AIR-S) constructs did not differ across the four groups, but the capacity, inclusion, and self-determination (SDS) constructs did differ. It was possible, however, to equate the mean values for the capacity, inclusion, and self-determination (SDS) constructs in the learning disability and other health impairment group, but not in the mild or moderate mental retardation group, which suggests differences based on level of cognitive impairment.

As shown in Table 8, students with learning disabilities and other health impairments are well above the mean on all three constructs; students with mild and moderate retardation, respectively, tended to score lower on each of the constructs. The widest disparity between the groups was on the inclusion construct, a finding supported by data that continue to suggest that students with more severe disabilities tend to be less likely to be included in general education settings (U.S. De- partment of Education, 2002). Additionally, as predicted, there were pronounced discrepancies across the groups on the capacity construct, suggesting that teachers perceive significant differences in students' capacity for self-determination based on level of intelligence. The differences in students' ratings of their own level of self-determination on the SDS also were significant but not as pronounced; and, contrary to expectations, students' ratings of their level of self-determination on the AIR-S did not differ significantly across the four groups.

Further, although there were differences in teachers' ratings on the capacity construct, there were not concomitant differences in their ratings on the opportunity construct. As discussed previously, there can be differences in students' abilities to develop the skills associated with self-determination which are based on their level of intelligence. Stereotypes about the ability of those students with intellectual disabilities to become self-determining potentially can influence both the number and quality of the opportunities, supports, and accommodations which can build on the capacity for self-determination. If high value is placed on the development of self-determination in students with more significant cognitive impairments, then a greater emphasis should be placed on providing frequent opportunities for such students to practice and refine the skills associated with self-determination-particularly be- 
cause students with more significant learning needs require more time to acquire the skills associated with self-determination (Wehmeyer, 2001).

Teachers, however, did not report the occurrence of greater opportunities for students with mild and moderate mental retardation to practice the skills associated with self-determination at school, even as they reported capacity differences. This pattern of results reinforces the importance of (a) educating teachers about the potential of students with a wide array of disabilities to become self-determining, and (b) supporting teachers and enabling them to implement opportunities for the development of the skills associated with self-determination at school. Research is needed to establish evidence-based practices that teachers can implement to support this outcome for students across disability groups (Algozzine et al., 2001). Strategies to overlap instruction in self-determination with ongoing classroom activities and requirements are important to these efforts. Flexible models of instruction that focus on teaching skills associated with self-determination and that can be implemented in conjunction with ongoing academic and functional skills instruction have been developed (e.g., "Self-Determined Learning Model of Instruction," Wehmeyer, Palmer, Agran, Mithaug, \& Martin, 2000). Teachers, however, continue to report having limited knowledge of such models of instruction (Wehmeyer, Agran, \& Hughes, 2000) and how to implement them in ongoing classroom activities.

As mentioned, the finding that students across the disability groups rated their level of self-determination differently on the SDS but not on the AIR-S deserves further examination. Previous research has suggested there are differences in the aspects of self-determination being assessed by the SDS and the AIR-S. Shogren, Wehmeyer, and colleagues (2006) found that the creation of a higher-order self-determination construct comprised of these two measures of self-determination was not justified, suggesting that each measure of self-determination is tapping into a different and unique aspect of the self-determination construct. Developing a greater understanding of the different aspects of self-determination being assessed by these two measures therefore is critical, as is exploring why the aspects of self-determination measured by the SDS tend to vary more based on disability category than do the aspects measured by the AIR-S. It is possible that the SDS is uncovering skills that are more influenced by level of intelligence, or that the SDS is more sensitive to detecting differences than is the AIR-S.

Given the wide use of the SDS and AIR-S in self-determination research, systematically examining the different aspects of self-determination that are being assessed by the two measures also is critical to understanding and interpreting the outcomes of interventions to promote self-determination. The research suggests that different outcomes could be obtained, for example, depending on the assessment of self-determination utilized. Additionally, the differences in students' ratings across the two measures, as well as the discrepancies between students' own ratings of their level of self-determination and teachers' ratings of the students' capacity for self-determination suggest that, in addition to supporting teachers in raising the expectations for students with disabilities, the students themselves need support in developing a realistic understanding of their individual levels of self-determination. Becoming self-aware and developing an understanding of one's strengths, limitations, and need for support are critical aspects of self-determination.

An interesting and unexpected finding is the lack of differences across the four groups in the students' ratings of their transition empowerment. The transition from school to adult life has received significant attention in the disability field during the last 20 years (Wehman, 2006), and perhaps the lack of differences in transition empowerment is indicative of the attention directed to involving all students with disabilities and their families in the transition-planning process. Although there were no differences across the disability groups, however, this finding should not be interpreted too optimistically. Ample evidence suggests that there are continued difficulties in implementing high-quality transition services. In fact, the mean rating across the 31 items on the TES was 2.5 (with a range of 1.7 to 3.3 ), suggesting that students are rating their empowerment in transition only slightly above average (using a scale response range of 0 to 4 ). 
An interesting and unexpected finding is the lack of differences across the four groups in the students' ratings of their transition empowerment.

Predictive Relationships. Given the finding at the measurement level that the latent variances and covariances did not differ across the disability groups, the data were collapsed across the four disability groups-after controlling for the meanlevel differences - to evaluate the degree to which capacity, opportunity, transition empowerment, and inclusion predicted self-determination as measured by the SDS and the AIR-S. The finding that there were no significant differences in the variances and covariances across the disability groups established that the pattern of predictive relationships was identical across the four disability groups.

Gender also was added as a covariate to determine its impact on the latent constructs. Interestingly, none of the other categorical variables of interest (race/ethnicity, free/reduced lunch status, and attendance at last IEP meeting) had an impact on self-determination scores. The only latent construct that gender significantly impacted was self-determination as measured by the SDS. On average, females tended to score higher than males by 0.19 standardized units. This finding corresponds with the findings of Soresi and colleagues (in press) but not with the findings of Wehmeyer and colleagues (Wehmeyer, 1996b; Wehmeyer \& Garner, 2003). Further research is needed to evaluate potential reasons for - and implications of-these gender differences in self-determination as measured by the SDS, as well as to confirm the findings related to the impact of the other categorical variables on a student's level of self-determination.

In analyzing the degree to which capacity, opportunity, transition empowerment, and inclusion predicted self-determination as measured by the SDS and AIR-S, an interesting pattern of findings emerged. First, contrary to expectations, teachers' ratings of students' opportunities for self-determination were not a significant predictor of self-determination as measured by the AIR-S, although the ratings were a significant predictor of self-determination as measured by the SDS. The finding that opportunities for self-determination did not predict self-determination as measured by the AIR-S suggests that, although teachers might perceive themselves as creating opportunities for self-determination at school, these opportunities are not impacting the aspects of self-determination measured by the AIR-S. This could be interpreted in several ways. First, perhaps opportunities presented outside of schoolwhich were not measured in this study —are more important predictors. It also is possible that, given special education teachers' reports in other studies that they lack understanding on how to effectively support student self-determination (Wehmeyer, Agran, et al., 2000), the opportunities that teachers perceive themselves as creating actually are not impacting students' level of self-determination as measured by the AIR-S. The finding that opportunities did predict self-determination as measured by the SDS, however, suggests that these opportunities could be having some impact, at least on the aspects of self-determination being measured by the SDS. It is important to note, however, that this relationship was the lowest significant path in the model. To understand the mechanism of the effect of opportunity on selfdetermination, further research is needed to evaluate (a) the relationship between the aspects of self-determination being measured by the SDS and the AIR-S, and (b) the reasons that opportunities for self-determination at school can differently impact students' self-reported levels of self-determination on these two measures.

With regard to the other predictors of selfdetermination, capacity predicted self-determination as measured by both the SDS and the AIR-S, but did so in very different ways. For self-determination as measured by the SDS, as hypothesized, capacity was a strong, positive predictor of self-determination (standardized $\beta=0.66$ ), suggesting both a clear relationship between capacity and the aspects of self-determination measured by the SDS, and the critical importance of capacity development as proposed by the functional theory of self-determination.

As measured by the AIR-S, however, capacity was a significant but negative predictor (standardized $\beta=-0.20$ ) of self-determination. This is an unexpected finding and suggests that teachers' 
ratings of students' capacity for self-determination were negatively related to students' own ratings of their level of self-determination. This could be due, in part, to the differences in the aspects of self-determination being measured by the AIR-S and the SDS and the low correspondence found throughout the analyses in teachers' and students' ratings on the AIR scales. For example, teachers reported significant differences in students' mean levels of capacity, measured by a subscale of the teacher report version of the AIR, but students across the disability groups did not report differences in their level of self-determination on the student report version of the AIR.

Previous research found low correspondence between the student and teacher report on the AIR (Shogren, Wehmeyer, et al., 2006), which suggests that teachers' ratings of students' capacity on the AIR might be of little value in understanding students' ratings of their overall level of selfdetermination on the AIR, and could explain the unexpected relationship between capacity and self-determination measured by the AIR-S. Additionally, because the SDS appears to be measuring different aspects of self-determination, perhaps teachers' ratings of students' capacity more accurately predict student self-determination on this assessment. Further research is needed to replicate and examine potential reasons for the unexpected, negative relationship between capacity and selfdetermination as measured by the AIR-S to determine whether it was an artifact of this particular study or if there are in fact significant differences in how students and teachers view and rate capacity for self-determination as measured by the AIR.

Research with adults has suggested that more inclusive living environments correlate with higher levels of self-determination. Contrary to expectations, however, inclusion was found to be a nonsignificant predictor of self-determination as measured by both the SDS and the AIR-S. This finding possibly can be interpreted within the context of Zhang's (2001) research, which suggests that students tend to display less self-determined behavior in general education settings, perhaps suggesting that inclusive settings in schools might not necessarily provide more opportunities for the development of self-determination. Further, given the finding that teachers did not rate opportunity for self-determination differently for students across the four disability groups - although the degree to which students were included did vary significantly across the four groups - these findings could suggest that there is a high degree of similarity in the opportunities for self-determination across different educational environments. Therefore, the degree to which a student is included could have little bearing on the development of self-determination. Research is needed to examine opportunities for self-determination across different educational settings; and to help develop strategies for promoting self-determination across different educational settings.

\section{Further research is needed to replicate and examine potential reasons for the unexpected, negative relationship between capacity and self-determination as measured by the AIR-S. .}

Lastly, transition empowerment, unlike the other latent constructs, was a significant and equivalent predictor of self-determination as measured by the SDS and AIR-S, although the standardized beta weight was higher for the relationship between transition empowerment and the AIR-S $(\beta=0.49)$, than for the SDS $(\beta=$ $0.33)$. This finding suggests the importance of empowering students to be involved in their education and their transition planning, and also highlights the potential of such efforts to increase students' level of self-determination. The categorical variable of the student's attendance at his or her last IEP meeting, however, was found to not significantly impact self-determination scores, which suggests that IEP meeting attendance does not by itself promote self-determination, instead it is active involvement and empowerment in the transition process that has the potential to impact self-determination.

\section{LIMITATIONS OF THE STUDY}

There exist several limitations to this study that must be considered in examining its implications. First, structural equation modeling does not allow researchers to draw conclusions regarding causal 
relationships; it instead provides a method to "test causal relationships with correlational data" and to "judge how consistent our causal model is with observed data" (Moore, 1995, p. 179). It cannot be concluded, for example, that transition empowerment causes self-determination; however, it can be said that the data are consistent with a causal model specifying this relationship. Therefore, although these analyses provide important information, experimental research is needed to further evaluate the causal relationships between the constructs included in the model. One of the outcomes of the 5-year intervention study that provided the baseline data for these analyses will be experimental data enabling further exploration of the relationships between the constructs specified in this model over time and as interventions to promote self-determination are implemented.

Additionally, there were limitations to the assessment materials and methods used in this study. Teachers and students each filled out multiple measures, which could have created dependency in the relationships between the measures completed by the different respondents. In examining the measurement models, the modification indices were systematically explored to determine whether there was any justification for allowing correlated residuals based on respondent, a way to control for this type of measurement error (Kline, 1998). No indication of the need for correlated residuals was found.

Further, for the inclusion construct only two appropriate manifest indicators were included. For self-determination measured by the AIR-S, because of the theoretical framework that defined the construct, only two appropriate facet-representative parcels were included. Generally, in SEM it is preferable to have three or more manifest indicators of each latent construct, to prevent model underidentification or estimation problems (Kline, 1998). Because of the study's sample size and the number of constructs included in the model, however, no problems with model estimation or identification were encountered. The SDS construct also had a low estimated latent variance in the measurement model, and research examining this finding is needed. The study also relied on information provided by teachers about the category under which students received special education services to assign students to disability groups for the analyses. The disability label of the participants was not independently verified. Future research should include the verification of the disability of each participant.

Last, the Home Opportunities subscale of the AIR was dropped from the analyses because a number of the participating teachers reported the inability to effectively report on students' opportunities for self-determination at home. To keep the AIR-S and AIR-E parallel, this subscale also was dropped from the AIR-S. Researchers also were unable to collect data using the parent version of the AIR. The lack of data on students' opportunities for self-determination at home, and on parents' perceptions of their children's capacity and opportunity for self-determination, is a significant limitation of this study - one that should be addressed in future research. Research also is needed to help develop and evaluate strategies for fostering effective communication and collaboration between parents and teachers with regard to promoting self-determination across home and school environments (Turnbull \& Turnbull, 2001a). Involving parents in this process is critical, particularly during the transition from school to adult life, because parents often continue to play integral roles in their children's lives after they exit school.

\section{IMPLICATIONS FOR FUTURE RESEARCH AND PRACTICE}

The findings of this study have several implications for future research and practice. First, as discussed, efforts to refine the assessment of self-determination, specifically developing a better understanding of the aspects of self-determination being measured by the SDS and the AIR-S, are critical to future research evaluating the impact of individual and ecological predictors as well as the impact of interventions to promote self-determination across diverse disability groups. For example, in evaluating interventions to promote self-determination, different outcomes could be obtained depending on the assessment utilized.

Continued work also is needed to educate, support, and empower students and teachers to understand and promote self-determination. It appears that the concerns regarding the capacity for self-determination of students having diverse 
disabilities can impact teachers' practices related to promoting self-determination (e.g., the opportunities provided) and this can influence students' reported level of self-determination. Strategies to promote student self-awareness and to support teachers in having high expectations with regard to their students' capacities for self-determination are needed.

Research also has suggested that, across disability categories, teachers frequently report not having sufficient training or information on how to promote self-determination within their classrooms (Wehmeyer, Agran, et al., 2000). This potentially is the reason for the finding that opportunities at school did not predict students' reported levels of self-determination on the AIR$\mathrm{S}$, and that inclusion did not predict self-determination as measured by the SDS or the AIR-S. Methods to promote self-determination across educational activities and settings must be developed, evaluated, and shared with teachers. Additionally, the finding that students' attendance at their IEP did not predict self-determination, but that students' rating of their transition empowerment did, suggests that such methods must work to foster multiple, interrelated opportunities for students to practice the skills and develop the attitudes associated with self-determined behavior to truly impact student's level of self-determination.

Given the identification of self-determination as the "ultimate goal of education" (Halloran, 1993 , p. 214 ); as a critical component of a successful transition to adulthood (Field, Martin, Miller, Ward, \& Wehmeyer, 1998); and as a core dimension of quality of life (Schalock, 1996), these findings suggest the importance of increased attention to preservice training on self-determination and its relevance to students with diverse disabilities, and the development and evaluation of methods to promote self-determination in students from diverse disability categories that take into account individual capacity and environmental opportunities for self-determination.

\section{REFERENCES}

Algozzine, B., Browder, D., Karvonen, M., Test, D. W., \& Wood, W. M. (2001). Effects of interventions to promote self-determination for individuals with disabilities. Review of Educational Research, 71(2), 219-277.

Cheung, G. W., \& Rensvold, R. B. (2002). Evaluating goodness-of-fit indexes for testing measurement invariance. Structural Equation Modeling, 9(2), 233-255.

Field, S., Martin, J., Miller, R., Ward, M., \& Wehmeyer, M. L. (1998). A practical guide to teaching selfdetermination. Reston, VA: Council for Exceptional Children.

Graham, J. W., Cumsille, P. E., \& Elek-Fisk, E. (2003). Methods for handling missing data. In J. A. Schinka \& W. F. Velicer (Eds.), Research methods in psychology (Vol. 2, pp. 87-114). New York: John Wiley \& Sons.

Halloran, W. D. (1993). Transition services requirement: Issues, implications, challenges. In R. C. Eaves \& P. J. McLaughlin (Eds.), Recent advances in special education and rehabilitation (pp. 210-224). Boston: Andover Medical Publishers.

Kline, R. B. (1998). Principles and practice of structural equation modeling. New York: Guilford Press.

Koren, P., DeChillo, N., \& Friesen, B. (1992). Measuring empowerment in families whose children have emotional disabilities: A brief questionnaire. Rehabilitation Psychology, 37(4), 305-321.

Little, T. D. (1997). Mean and covariance structures (MACS) analyses of cross-cultural data: Practical and theoretical issues. Multivariate Behavioral Research, 32(5), 53-76.

Little, T. D., Cunningham, W. A., Shahar, G., \& Widaman, K. F. (2002). To parcel or not to parcel: Exploring the question, weighing the merits. Structural Equation Modeling, 9(2), 151-173.

Little, T. D., Slegers, D. W., \& Card, N. A. (2006). A non-arbitrary method of identifying and scaling latent variables in SEM and MACS models. Structural Equation Modeling, 13(1), 59-72.

Mithaug, D. E., Campeau, P. L., \& Wolman, J. M. (2003). Assessing self-determination prospects among students with and without disabilities. In D. E. Mithaug, D. K. Mithaug, M. Agran, J. E. Martin, \& M. L. Wehmeyer (Eds.), Self determined learning theory: Construction, verification, and evaluation (pp. 61-76). Mahwah, NJ: Lawrence Erlbaum.

Moore, A. D. (1995). Structural equation modeling in special education research. Remedial and Special Education, 16(3), 178-183.

Powers, L. E., Ellison, R., Matuszewski, J., Wilson, R., Phillips, A., \& Rein, C. (2001). A multi-component intervention to promote adolescent self-determination. Journal of Rehabilitation, 67(4), 13-19. 
Powers, L. E., Turner, A., Westwood, D., Matuszewski, J., Wilson, R., \& Phillips, A. (2001). TAKE CHARGE for the Future: A controlled field-test of a model to promote student involvement in transition planning. Career Development for Exceptional Individuals, 24(1), 89-103.

Schalock, R. L. (1996). Reconsidering the conceptualization and measurement of quality of life. In R. L. Schalock (Ed.), Quality of life: Conceptualization and measurement (Vol. 1, pp. 123-139). Washington, DC: American Association on Mental Retardation.

Shogren, K. A., Lopez, S. J., Wehmeyer, M. L., Little, T. D., \& Pressgrove, C. L. (2006). The role of positive psychology constructs in predicting life satisfaction in adolescents with and without cognitive disabilities: An exploratory study. The Journal of Positive Psychology, 1(1), 37-52.

Shogren, K. A., \& Turnbull, A. P. (2006). Promoting self-determination in young children with disabilities: The critical role of families. Infants and Young Children, 19(4), 338-352.

Shogren, K. A., Wehmeyer, M. L., Palmer, S. B., Soukup, J. H., Little, T. D., Garner, N., et al. (2006). Measuring self-determination: Examining the relationship between The Arc's Self-Determination Scale and the AIR Self-Determination Scale (Manuscript submitted for publication).

Soresi, A., Nota, L., \& Wehmeyer, M. L. (in press). Self-determination, social abilities, and the quality of life of people with intellectual disabilities. Journal of Intellectual Disability Research.

Stancliffe, R. J., Abery, B. H., \& Smith, J. (2000). Personal control and the ecology of community living settings: Beyond living-unit size and type. American Journal on Mental Retardation, 105(6), 431-454.

Trainor, A. (2002). Self-determination for students with learning disabilities: Is it a universal value? International Journal of Qualitative Studies in Education, 15(6), 711-725.

Trainor, A. (2005). Self-determination perceptions and behaviors of diverse students with LD during the transition planning process. Journal of Learning Disabilities, 38(3), 233-248.

Turnbull, A. P., \& Turnbull, H. R. (1997). Self-determination within a culturally responsive family systems perspective. In L. E. Powers, G. H. S. Singer, \& J. Sowers (Eds.), On the road to autonomy: Promoting self-competence in children and youth with disabilities (pp. 195-220). Baltimore: Brookes.

Turnbull, A. P., \& Turnbull, H. R. (2001a). Families, professionals, and exceptionality: Collaborating for em- powerment. Upper Saddle River, NJ: Merrill Prentice Hall.

Turnbull, A. P., \& Turnbull, H. R. (2001b). Self-determination for individuals with significant cognitive disabilities and their families. Journal of the Association for Persons with Severe Handicaps, 26(1), 56-62.

U.S. Department of Education. (2002). 24th annual report to Congress on the implementation of the Individuals with Disabilities Education Act. Washington DC: U.S. Department of Education.

Wehman, P. (2006). Life beyond the classroom: Transition strategies for young people with disabilities (4th ed.). Baltimore, MD: Paul H. Brookes.

Wehmeyer, M. L. (1996a). Self-determination as an educational outcome: Why is it important to children, youth and adults with disabilities? In D. J. Sands \& M. L. Wehmeyer (Eds.), Self-determination across the life span: Independence and choice for people with disabilities (pp. 15-34). Baltimore, MD: Paul H. Brookes.

Wehmeyer, M. L. (1996b). A self-report measure of self-determination for adolescents with cognitive disabilities. Education and Training in Mental Retardation and Developmental Disabilities, 31, 282-293.

Wehmeyer, M. L. (1996c). Student self-report measure of self-determination for students with cognitive disabilities. Education and Training in Mental Retardation and Developmental Disabilities, 31(4), 282-293.

Wehmeyer, M. L. (1997). Self-determination as an educational outcome: A definitional framework and implications for intervention. Journal of Developmental and Physical Disabilities, 9(3), 175-209.

Wehmeyer, M. L. (1999). A functional model of selfdetermination: Describing development and implementing instruction. Focus on Autism and Other Developmental Disabilities, 14(1), 53-61.

Wehmeyer, M. L. (2001). Self-determination and mental retardation. In L. M. Glidden (Ed.), International review of research in mental retardation (Vol. 24, pp. 1-48). San Diego, CA: Academic Press.

Wehmeyer, M. L. (2003). A functional theory of selfdetermination: Model overview. In M. L. Wehmeyer, B. Abery, D. E. Mithaug, \& R. Stancliffe (Eds.), Theory in self-determination: Foundations for educational practice. Springfield, IL: Charles C Thomas.

Wehmeyer, M. L. (2006). Self-determination and individuals with severe disabilities: Re-examining meanings and misinterpretations. Research and Practice for Persons with Severe Disabilities, 30(3), 113-120.

Wehmeyer, M. L., Abery, B., Mithaug, D. E., \& Stancliffe, R. (2003). Theory in self-determination: Founda- 
tions for educational practice. Springfield, IL: Charles C Thomas.

Wehmeyer, M. L., Agran, M., \& Hughes, C. (2000). A national survey of teachers' promotion of self-determination and student-directed learning. Journal of Special Education, 34(2), 58-68.

Wehmeyer, M. L., \& Bolding, N. (1999). Self-determination across living and working environments: A matched-samples study of adults with mental retardation. Mental Retardation, 37(5), 353-363.

Wehmeyer, M. L., \& Bolding, N. (2001). Enhanced self-determination of adults with intellectual disability as an outcome of moving to community-based work or living environments. Journal of Intellectual Disability Research, 45(5), 371-383.

Wehmeyer, M. L., \& Garner, N. W. (2003). The impact of personal characteristics of people with intellectual and developmental disability on self-determination and autonomous functioning. Journal of Applied Research in Intellectual Disabilities, 16, 255-265.

Wehmeyer, M. L., \& Kelchner, K. (1995). The Arc's Self-Determination Scale. Arlington, TX: The Arc National Headquarters.

Wehmeyer, M. L., Palmer, S. B., Agran, M., Mithaug, D. E., \& Martin, J. E. (2000). Promoting causal agency: The Self-Determined Learning Model of Instruction. Exceptional Children, 66, 439-453.

Wolman, J., Campeau, P., Dubois, P., Mithaug, D., \& Stolarski, V. (1994) AIR Self-Determination Scale and user guide. Palo Alto, CA: American Institute for Research.

Wood, W. M., \& Test, D. W. (2001). Final performance report: Self-determination synthesis project. Charlotte, NC: University of North Carolina at Charlotte.
Zhang, D. (2001). Self-determination and inclusion: Are students with mild mental retardation more selfdetermined in regular classrooms? Education and Training in Mental Retardation and Developmental Disabilities, 36(4), 357-362.

\section{ABOUT THE AUTHORS}

KARRIE A. SHOGREN (CEC TX Federation), Assistant Professor, Department of Special Education, University of Texas at Austin. MICHAEL L. WEHMEYER (CEC KS Federation), Professor, Department of Special Education, University of Kansas, Lawrence. SuSAN B. PALMER (CEC KS Federation), Research Associate Professor; and JANE HELEN SOUKUP (CEC KS Federation), Research Assistant Professor, Beach Center on Disability, University of Kansas, Lawrence. TODD D. Litrle, Professor, Department of Psychology, University of Kansas, Lawrence. NANCY GARNER (CEC TX Federation), Project Manager; and MARGARET LAWRENCE (CEC TX Federation), Project Coordinator, Beach Center on Disability, University of Kansas, Lawrence.

Address correspondence to Karrie A. Shogren, University of Texas at Austin, 1 University Station/D5300, Austin, TX 78712 (e-mail: shogren@mail.utexas.edu).

Manuscript received May 2006; accepted November 2006.

\section{Federal Outlook for Exceptional Children Fiscal Year 2008}

\section{Budget Considerations and CEC Recommendations}

This latest update provides data on federal appropriations for all the major programs affecting special education. It gives a summary of each program, including purpose, funding, the types of activities it supports, fiscal considerations, and CEC recommendations.

$$
\text { 2007, } 80 \text { pages. }
$$

\#R5835 \$23.95 / CEC Members \$17.95

To order call 1-888-232-7733

or visit us online at www.cec.sped.org

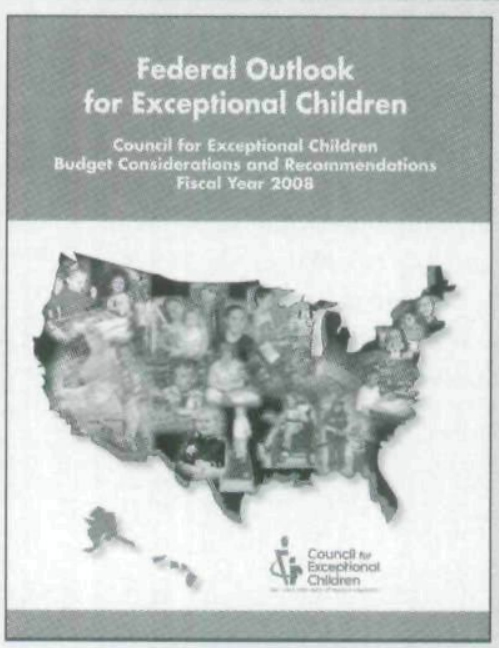


Copyright of Exceptional Children is the property of Council for Exceptional Children and its content may not be copied or emailed to multiple sites or posted to a listserv without the copyright holder's express written permission. However, users may print, download, or email articles for individual use. 